case of three Arctic foxes from Iceland in the Zoological Gardens, of which " one turns perfectly white every winter, while the other two remain dark."

Cambridge, November 12 .

\section{W. F. Lanchester.}

The Magnetic Storm of October 31.

Dr. Glazebrook has asked me to send you a copy of one or more of the magnetic curves during the late storm, and also of a characteristically "quiet" day. For the latter I

ment, which was partly lost on our own magnetograph, the scale of ordinates of which is more open. In this curve $\mathrm{I} \mathrm{mm}$. represents in the original very nearly $\mathrm{I}^{\prime}$ of arc and increasing ordinate decreasing westerly declination. We had not set the clock driving this instrument quite correct, and the times shown in the trace are about four minutes wrong.

During the rapid movements the traces on the originals are faint, and consequently are not fully shown in the photographic copies sent you.

I ought to explain that the slight blurring and want of clearness on the horizontal force trace October 29-31 really arise from the electric trams. Their action, however, is hardly visible during the storm proper in either declination or horizontal force. In the vertical force, however-of which no copy is sent-the electric tram disturbance is much more considerable, and might easily be mistaken by the uninitiated for a fairly active magnetic storm.

In the accompanying illustrations, Figs. I and 2 , I $\mathrm{cm}$. represents practically $4 \mathrm{~cm}$. of the original curves. SUPERINTENDENT OBSERVATORY DEPARTMENT.

The National Physical Laboratory, Richmond, Surrey, November 7 .

\title{
Expansion Curves.
}

In your issue of October 8 Prof. John Perry describes in a letter. "an exceedingly simple, ingenious method", of plotting. the so-called polytropic curve representing the law $p v^{n}=$ constant, which method he found in a pamphlet by Mr. E. J. Stoddard, of

FIfi. 1.-Reduced Registes s of Horizontal Force.

send copy of declination October $2-3,1900, B_{1}$, Fig. 2 . It is not absolutely quiet-very few days are, if any-and parts show the tiny "magnetic waves" of ten met with. Here, as usual, there are two days' curves, each with its own base (or time) line on the same sheet. The paper is changed every second day, shortly after io a.m. In this quiet day declination curve, $\mathrm{I} \mathrm{cm}$. of ordinate in the original represents $8^{\prime} .7$, and increasing ordinate answers to increasing westerly declination.

The magnetic storm on October $3 I$ commenced about four hours before the papers were changed, and the assistant in charge, noticing that a storm was in progress, arranged that the papers should be changed again next day, so as to have only one day's trace on the sheet, and so no mixing of two days' traces. As the commencement at $6.3 \mathrm{a} . \mathrm{m}$. is of interest, I am sending two sheets of the horizontal force record Fig. I, the one, $A_{1}$, covering the interval October 29, 10.40 a.m., to October 3I, Io.16 a.m., the other, $A_{2}$, October $3 I$, I0.21 a.m., to November I, 10.42 a.m. On October 31 some of the trace is off the sheet about io a.m., also between 2 and 4 p.m. and between 5 and 7 p.m. The time or base line answers to an arbitrary value (determined by the absolute observations), and $\mathrm{r} \mathrm{cm}$. of ordinate in the original curve represents $50 \gamma$ (where $\mathrm{I} \gamma=\mathrm{I} \times \mathrm{IO}^{-5}$ C.G.S.), increasing ordinate representing increasing force.

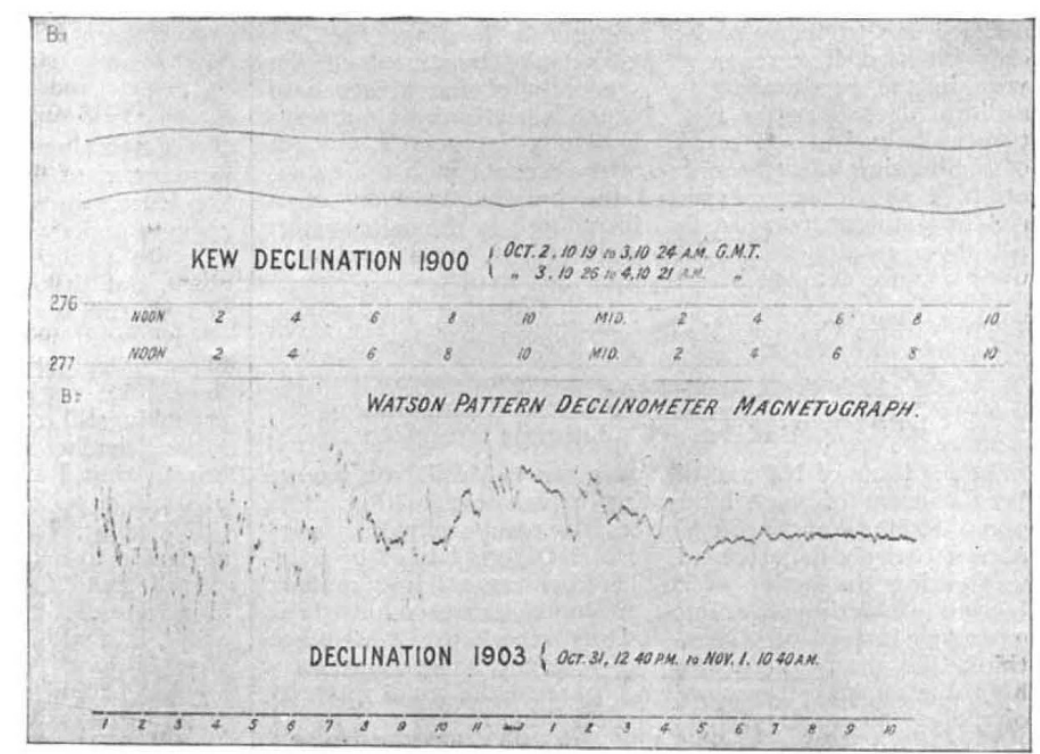

FIG. 2.-Reduved Registers of Decliuation.

publication this method has been used in a number of treatises on thermodynamics published in Germany and France. It has been given for years in the very valuable handbook "Huette," which is undoubtedly known to Prof. Detroit. I may be permitted to state that this method was published for the first time eighteen years ago by Prof. E. Brauer in the Transactions of the Society of German Engineers, 1885, p. 433, and since Prof. Brauer's

Fig 2 given by a Watson pattern magneton record the Cambridge Instrument Company, sent to the L atory for test. The original shows, I think, all the move.

No. I 777 , vOL. 69] 